\title{
An amputated appendicitis: should we search for distal amputated part?
}

\author{
Sajad Ahmad Wani, Gowher Nazir Mufti, Raashid Hamid, Nisar Ahmad Bhat, Aejaz Ahsan Baba \\ Department of Paediatric Surgery, SKIMS Soura Srinagar, Jammu and Kashmir, India
}

Received: July 13, 2015

DOI: $10.5430 /$ css.v1n1p54
Accepted: July 28, 2015

URL: http://dx.doi.org/10.5430/css.v1n1p54

\begin{abstract}
The aim of these case reports is to discuss the necessity of searching for distal amputated part in amputated appendicitis. It is important to search for distal part of appendix in complicated (amputated) appendicitis. Surgeons must take great care to ensure that no part of the appendix remains, to prevent the morbidity of further laparotomies in cases of distal residual appendicitis.
\end{abstract}

Key Words: Amputated appendicitis, Incomplete appendectomy, Distal residual appendicitis

\section{INTRODUCTION}

Acute appendicitis is a common surgical emergency. Appendectomy is a relatively simple surgical procedure but it is not free of complications, one of them is appendicitis of residual stump which can occur from three weeks to twenty three years after appendectomy. ${ }^{[1,2]}$ The diagnosis of such complication remains challenging despite advances in minimally invasive surgery and radiology. Appendicitis in distal residual appendix after appendectomy is a very rare entity and should be considered in the differential diagnosis of localized peritonitis in a patient with previous history of appendectomy. ${ }^{[3]}$ Stump appendicitis is an acute inflammation of the residual appendicial stump and there are about 70 such cases reported in the English literature, but appendicitis of distal amputated remnant appendix is very scarce in literature.

Clinician should a have an index of suspicion for residual appendicitis in patients with history of appendectomy and who present with acute appendicitis like picture. ${ }^{[4]}$ Patient may present with recurrent pain in right lower quadrant, ten- derness, fever, abscess formation or peritonitis. Ultrasonography and computed tomography may play role in diagnosis of residual appendicitis. ${ }^{[5]}$ Surgical error commonly described is the inability in identifying the distal amputated part after treating the appendicular stump during the initial operation of appendectomy in amputated appendicitis. We describe 2 cases of post appendectomy distal residual appendicitis.

\section{Case presentation}

\subsection{Case 1}

Three year old male child was admitted in our department with complaints of pain abdomen, vomiting, and tenderness in right lumber region. There was history of open appendectomy four months back at district hospital. Operative findings were lump formation, pus, gangrenous appendix and unhealthy base. Complete blood count was showing leucocytosis with neutrophelia and urine examination was normal. Ultrasonography was unremarkable and computed tomography was showing blind ended apparistaltic tubular structure behind the caecum (see Figure 1). On exploration, distal rem-

*Correspondence: Sajad Ahmad Wani; Email: ahmadsajadwani@gmail.com; Address: Married doctors Hostel A- Block Room NO.-F5 SKIMS Soura Srinagar, Jammu and Kashmir, India. 
nant inflamed appendix was found retrocaecal (see Figure 2). Completion appendectomy was done and histopathological examination showed features of appendicitis. Postoperative period was uneventful and patient was discharged on third postoperative day.

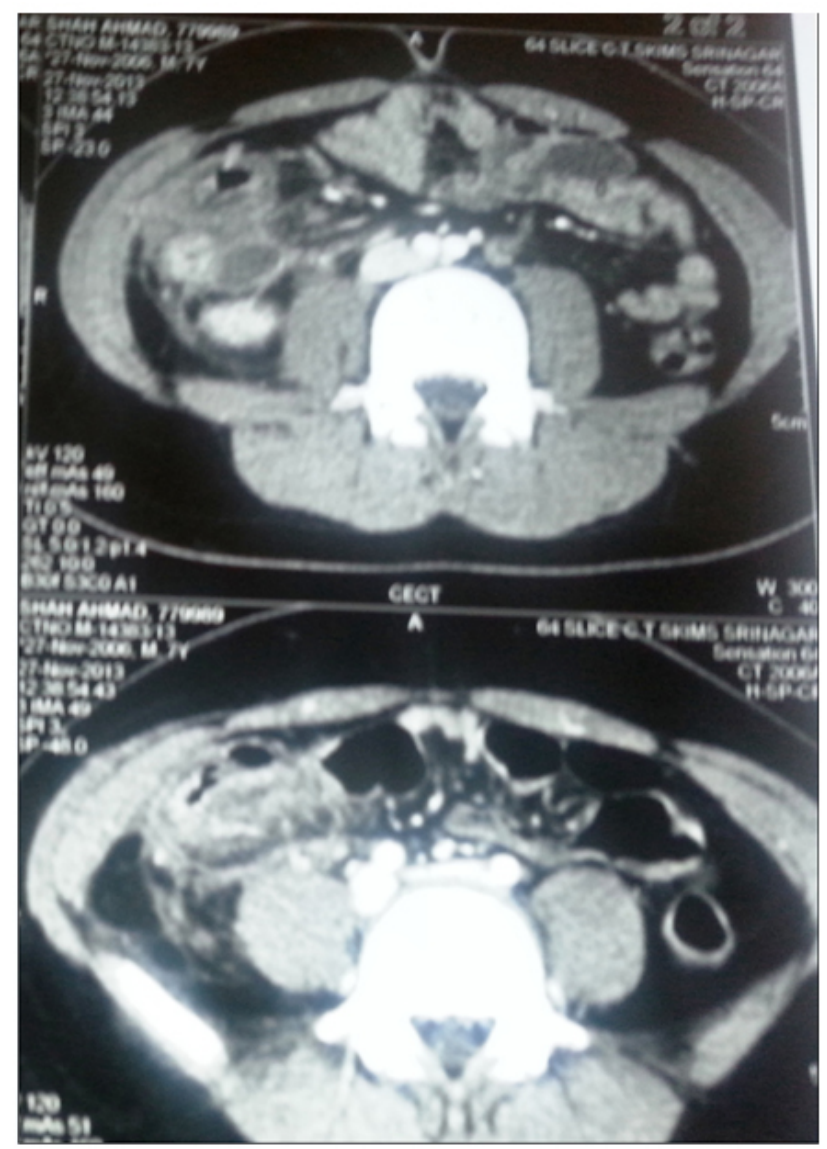

Figure 1. Tubular structure behind the caecum

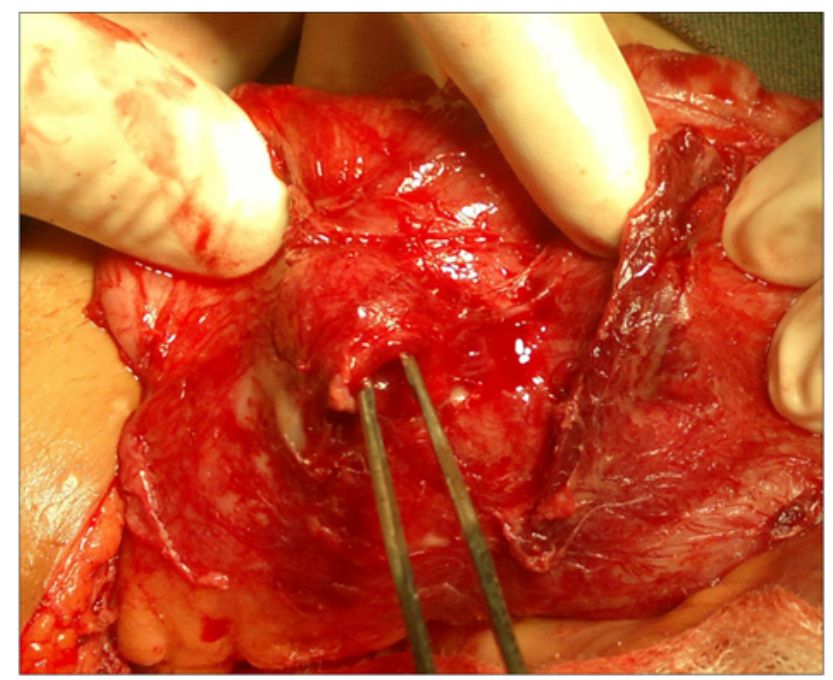

Figure 2. Distal remnant inflamed appendix

\subsection{Case 2}

Eleven year old male was admitted in our department as a case of post appendectomy pain abdomen, fever with tenderness in right lower abdomen. Open appendectomy was done 9 months back, but operative records were not available. Complete blood count was showing leucocytosis with neutrophelia. Ultrasonography (USG) was showing lump formation in right iliac fossa and computed tomography was showing lump formation with collection in right iliac fossa. On exploration, collection was drained and distal remnant appendix was found retrocaecal which was grossly inflamed (see Figure 3). Completion appendectomy was done and histopathological examination showed features of appendicitis. Postoperative period was uneventful and patient was discharged on fourth postoperative day.

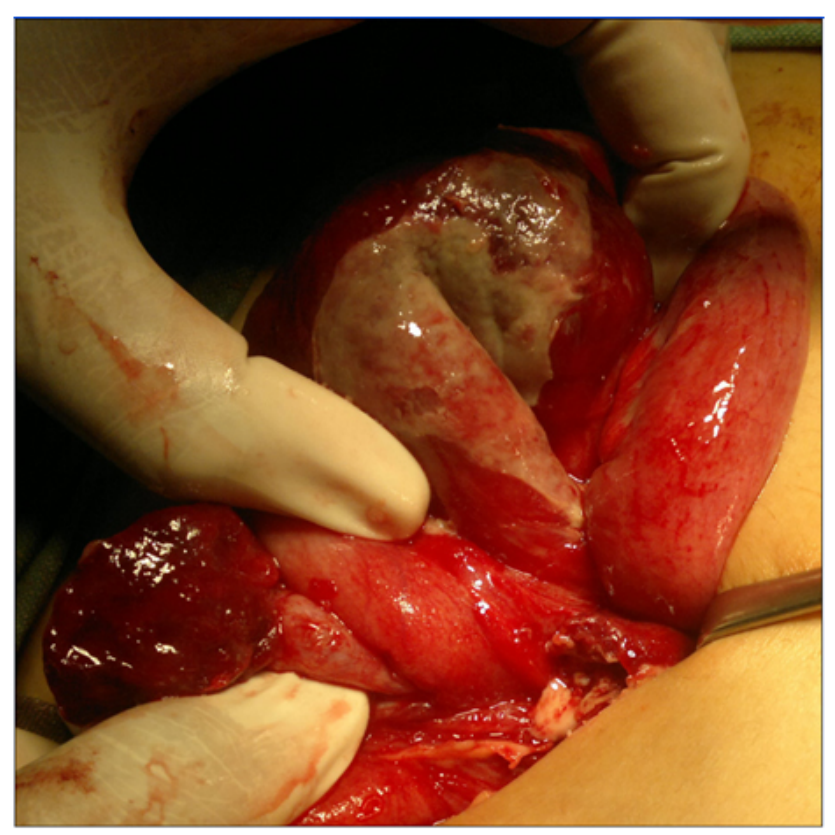

Figure 3. Inflamed retrocaecal distal remnant appendix

\section{Discussion}

Appendectomy is one of the frequent abdominal emergency surgical procedures in paediatric age group. Postoperative complications are unusual, but in complicated gangrenous amputated appendicitis post operative complications include, wound infection, abscess formation, adhesions, and later on stump appendicitis or appendicitis of residual distal remnant which is a rare complication and is difficult to diagnose. There are about 70 cases of stump appendicitis reported in literature but only few cases of distal remnant appendicitis have been reported. Post appendectomy appendicitis should be kept in mind in a patient with persistent or late onset of signs and symptoms of appendicitis. The cause is incomplete removal of appendix in difficult, perforated, ruptured and 
amputated appendicitis. The presence of local peritonitis, adhesions, oedema, abscess, preileal, subserosal appendix are related factors leading to incomplete removal of appendix. ${ }^{[6]}$

Clinical presentation of residual distal remnant appendicitis is more or less similar to the severe appendicitis. Ultrasonography can be diagnostic in distal remnant appendicitis, but in our patients it has not helped so much may be because it is operator dependant. Computed tomography has definite role in the diagnosis of residual appendicitis. ${ }^{[5,7]}$ The diagnostic laparoscopy is quite useful while being also therapeutic. Despite all the diagnostic modalities, sometimes it is not possible to reach the final diagnosis. In our patients, diagnosis in one patient was made by computed tomography and in second patient diagnosis was suspected on clinical grounds and confirmed on laparotomy.

Residual appendicitis has been reported most frequently in cases of appendicitis treated with laparoscopic surgery. ${ }^{[3]}$ The treatment of appendicitis of residual remnant appendix is most commonly reported as an open operation but cases have been successfully treated by laparoscopic intervention and the treatment is completion appendectomy. ${ }^{[3]}$ We did completion appendectomy via laparotomy in both the cases because of suspicion of adhesions from previous surgery.

\section{Conclusion}

Correct identification and removal of the distal appendix in complicated amputated appendicitis minimizes the risk of future distal residual appendicitis and hence morbidity from additional laparotomy. It is necessary to search the distal part of appendix in amputated appendicitis. If there is any difficulty in searching the amputated part, help from senior surgeon should be sought.

\section{REFERENCES}

[1] Siegel SA. Appendiceal stump abscess: a report of stump abscess twenty-three years postappendectomy. The American Journal of Surgery. 1954; 63: 630-2. http://dx.doi.org/10.1016/000 2-9610 (54) 90306-2

[2] Baumgardner LO. Rupture of appendiceal stump three months after uneventful appendicectomy with repair and recovery. Ohio State Medical Journal. 1949; 45: 476-7.

[3] O'Leary DP, Myers E, Coyle J, et al. Case report of recurrent acute appendicitis in a residual tip. Cases J. 2010; 3: 14. PMid: 20157645 http://dx.doi.org/10.1186/1757-1626-3-14

[4] Al-Dabbagh AK, Thomas NB, Haboubi N. Stump appendicitis: a

diagnostic dilemma. Techniques in Coloproctology. 2009; 13: 73 4. PMid: 18545872. http://dx.doi.org/10.1007/s10151-0 08-0419-5

[5] Romesburg J, Imam K. Stump appendicitis. Applied Radiology. 2010; 39: $36-8$.

[6] Subramanian A, Liang MK. A 60-year literature review of stump appendicitis: the need for a critical view. http://dx.doi.org/10 . 1016/j.amjsurg. 2011.04.009

[7] Salehi H, Anjamrooz SH. Successfully treated stump appendicitis diagnosed by CT and ultrasonography. Indian Journal of Surgery. 2008; 70: 89-1. PMid: 23133030. http://dx.doi.org/10.1007 /s12262-008-0024-x 